\title{
Contatos imediatos Brasil e Argentina: Adhemar Gonzaga em Buenos Aires ${ }^{1}$
}

/////////////////// : Arthur Autran ${ }^{2}$

1. Este artigo foi desenvolvido com o apoio do Conselho Nacional de Desenvolvimento Científico e Tecnológico por meio do Edital 07/2011. Uma primeira versão foi apresentada no XVI Encontro da Socine, ocorrido no Centro Universitário Senac, em São Paulo.

2. Doutor pelo Instituto de Artes da Unicamp. É professor do Departamento de Artes e Comunicação da Universidade Federal de São Carlos. Bolsista PQ nível 2 do CNPq. E-mail: autran@ufscar.br. 
Resumo Este artigo enfoca as relações entre as cinematografias da Argentina e do Brasil nas décadas de 1930 e 1940, tendo como eixo central a visita de Adhemar Gonzaga a Buenos Aires em 1934 e os contatos ali estabelecidos. O artigo também aborda a excursão do astro de Hollywood Ramón Novarro pela América do Sul, uma das motivações da viagem de Gonzaga.

Palavras-chave História do cinema, cinema brasileiro, cinema argentino, Hollywood.

Abstract This paper focuses on the relations between the cinematography of Argentina and the cinematography of Brazil in the 1930s and 1940s, with the central axis Adhemar Gonzaga's visit to Buenos Aires in 1934 and the contacts established there. The paper also discusses the tour of Hollywood star Ramón Novarro in South America, one of the motivations of the trip of Gonzaga.

Keywords Film history, Brazilian cinema, Argentine cinema, Hollywood. 
3. Este artigo não seria possível sem o material coletado no Arquivo Cinédia. Agradeço a D. Alice Gonzaga pelo acesso. Agradeço também a Carlos Roberto de Souza, que me indicou fontes e referências bibliográficas fundamentais para a pesquisa.

4. As traduções para o português neste artigo foram feitas pelo autor.

\section{Introdução}

A partir da análise dos discursos historiográficos a respeito da trajetória das cinematografias da Argentina e do Brasil entre 1930 e 1945, este artigo discorre sobre os intercâmbios ocorridos entre elas ao longo do período mencionado, com destaque para a passagem de Adhemar Gonzaga por Buenos Aires em $1934^{3}$.

Em primeiro lugar, é preciso notar que, no caso da Argentina, a historiografia clássica do cinema indica o período que vai de 1933 até 1942 como "la época de oro", título da parte referente a esse interregno de tempo no livro fundador da historiografia daquele país, escrito pelo crítico Domingo di Núbila e cuja primeira edição data de 1960. Isso porque no período 1933-1942 surgiram: os estúdios Argentina Sono Films, Lumiton, Pampa Film e San Miguel, entre outros; um star system com artistas como Hugo Del Carril, Libertad Lamarque, Luis Sandrini, Niní Marshall e Tita Merello; diretores como Francisco Mugica, Lucas Demare, Luis Saslavsky, Manuel Romero e Mario Soffici. Outrossim, houve consistente avanço do produto nacional no mercado interno e no latino-americano. O auge desse processo ocorre com o lançamento e o sucesso de público e crítica de A guerra gaúcha (La guerra gaucha, Lucas Demare, 1942), que, para Di Núbila: "Foi a película de maior êxito do cinema argentino e também uma das melhores"4 (1998, p. 392).

Muito outra foi a situação brasileira ao longo dos anos 1930 até o final da $2^{\mathrm{a}}$ Guerra Mundial, cujas experiências industriais 
5. Sem negar que a concorrência comercial levou os Estados Unidos a restringir a exportação de filme virgem para a Argentina, é de observar que outra razão para a restrição foi a posição neutra assumida por este país na maior parte da Segunda Guerra Mundial, pois o filme virgem era considerado insumo estratégico pelos Estados Unidos (GETINO, 1998, p. 37-38). surgidas no início da década, tais como a Cinédia e a Brasil Vita Film, fracassaram em termos econômicos. O quadro brasileiro ficou caracterizado pela pequena produção de filmes de ficção e a manutenção da atividade por meio da produção de curtasmetragens e cinejornais, os quais eram exibidos compulsoriamente por meio da lei 21.240 de 1932. Essa situação levou Alex Viany (1959, p. 100), na sua obra fundadora Introdução ao cinema brasileiro, publicada em 1959, a considerar que, após o advento do som, o cinema brasileiro seria como "um rapazinho inteligente que, exatamente ao atingir a maioridade, levara um tombo e voltara ao tatibitate".

E se a Argentina, segundo César Maranghello, em 1942, "constituía um perigo real" para os lucros da indústria norteamericana de cinema ao ponto de os Estados Unidos diminuírem o fornecimento de filme virgem a fim de prejudicar a produção do país sul-americano (MARANGHELLO, 2005, p. 112)후 já no Brasil, ao longo dos anos 1930 e 1940, o contexto da produção local, na visão de Paulo Emílio Salles Gomes (1980, p. 32), era marcado por:

\footnotetext{
Algumas leis paternalistas de amparo asseguram o prolongamento dos péssimos jornais cinematográficos e, numa fase posterior, obrigam as salas a exibir uma pequena percentagem de filmes brasileiros de enredo.
}

É possível perceber que a diferença entre a situação concreta da produção de ambos os países no período levou a que o tom do discurso historiográfico acerca dele fosse bem distinto. Mais do que isso: a própria dedicação dos historiadores também apresenta notável discrepância, pois se, na Argentina, a década de 1930 até hoje é tema de artigos e livros, no Brasil, só recentemente o período parece ter despertado algumas análises mais percucientes.

Ainda em relação à historiografia clássica, há diversos elementos comuns no discurso historiográfico: narrativas que se pretendem um panorama totalizador a respeito do passado cinematográfico nacional; a inspiração no modelo ditado por Georges Sadoul; a teleologia; a centralidade da produção em detrimento de outras áreas; a importância da constituição do cânone artístico etc. 
Quanto à produção historiográfica contemporânea, podemos destacar trabalhos como os de Raúl Horacio Campodónico (2005), Ana Laura Lusnich (2007) e Rafael de Luna Freire (2011). Trincheras de celuloide, de Campodónico, a partir de uma perspectiva bastante crítica em relação à historiografia clássica do cinema argentino representada, sobretudo, por autores como Domingo di Núbila -, proporciona ampla discussão sobre as relações entre cinema e Estado de 1933 a 1958, cobrindo as diferentes formas de intervenção estatal - censura, pressões políticas, medidas protecionistas, financiamento etc. - em todo o período da produção industrial no país vizinho. Já El drama social-folclórico, obra originada da tese de doutorado de Ana Laura Lusnich, objetiva estudar um dos principais "modelos cinematográficos" argentinos no marco que vai de 1933 a 1956, elaborando uma criteriosa divisão de tipos de drama ambientado no campo a partir dos quais a autora busca entender a estrutura narrativa, o sistema de personagens, a constituição das imagens etc. Quanto a Carnaval, mistério e gangsters, tese de doutoramento de Rafael de Luna Freire ainda inédita na forma de livro, a partir de uma discussão aprofundada em torno dos gêneros, busca-se historicizar o filme policial no quadro do cinema brasileiro entre 1915 e 1951. Um primeiro dado que chama a atenção nesses estudos é que eles evitam o recorte panorâmico e constituem de forma clara os seus objetos de pesquisa; outro dado que deve ser destacado é a conciliação entre a pesquisa em relação às fontes (sejam os filmes propriamente ditos, sejam textos críticos mais ou menos contemporâneos ao lançamento dos filmes, sejam documentos legais, entre outros) e a verticalização da discussão teórica (de cunho historiográfico, das teorias sobre gênero ou das teorias sobre a narração etc.).

\section{Os intercâmbios entre Argentina e Brasil no campo do cinema}

Ontem como hoje permanece na sombra uma questão: qual a relação entre as cinematografias dos dois países ao longo do período 1930-1945? Trata-se de uma problemática ainda praticamente intocada pela historiografia, como, aliás, pouco se discutem também os intercâmbios em outros períodos. A pouca atenção para com as 
relações entre as duas cinematografias deve-se a uma característica da historiografia já apontada por Paulo Antônio Paranaguá: o recorte ser determinado pelas fronteiras nacionais. $\mathrm{O}$ mesmo autor observa que isso já é quase naturalizado na história do cinema, e os primeiros trabalhos canônicos do campo de estudos recorriam a esse tipo de recorte (PARANAGUÁ, 2000, p. 109).

Ao contrário do que se possa pensar, não se tratava de algo estanque, ou seja, cada país encapsulado na sua luta contra o produto norte-americano - dominante em ambos os mercados e buscando bravamente construir a sua própria indústria de filmes.

O sinal mais evidente de que havia trocas se relaciona com o fato de as fitas argentinas de sucesso terem sido comercializadas no mercado brasileiro. Por exemplo, a comédia Riachuelo (Luis Moglia Barth, 1934), com Luis Sandrini à frente do elenco, foi exibida em São Paulo no cine Glória em outubro de 1935 (Correio Paulistano, 13 out. 1935, p. 10). Trata-se de uma comédia importante, pois, para além do público alcançado na Argentina, ela apresenta tipos populares e situações cômicas que marcaram a produção do país vizinho. Madreselva (Luis César Amadori, 1938), película estrelada por Libertad Lamarque, foi exibida a partir das 14 horas do dia 12 de fevereiro de 1939 no cine Rosário, também em São Paulo, e o anúncio publicitário divulga ainda que na mesma sala haveria duas sessões, às $16 \mathrm{~h} 20$ e às $21 \mathrm{~h} 20$, com a atriz e cantora se apresentando no palco - ela é chamada no anúncio de “a alma da canção argentina" (Folha da Manhã, 12 fev. 1939, p. 7). O já citado A guerra gaúcha também passou no Brasil, conforme anúncios que divulgam sua exibição em dezembro de 1944, no Pathé, no Rio de Janeiro (Correio da Manhã, 19 dez. 1944, p. 1). E, pelo menos no caso de Bonequinha de seda (Oduvaldo Viana, 1936), uma produção da Cinédia, houve a tentativa brasileira de alcançar o mercado portenho (GONZAGA, 1987, p. 66).

Para além dos filmes, também havia circulação de profissionais. Oduvaldo Viana, o diretor de Bonequinha de seda e já então conhecido como dramaturgo, viajou em 1938 para a Argentina e lá realizou a fita El hombre que nació dos veces (1938). Ademais, ele teve adaptada para o cinema a sua peça Amor: o filme de título homônimo foi dirigido por Luis Bayón Herrera em 1940. 
Em outra chave, mais ligada ao intercâmbio cultural, merece ser mencionado Embrujo (Enrique Susini, 1941), filme da Lumiton que ficcionaliza o romance entre D. Pedro I e D. Domitila de Castro, com Jorge Rigaud no papel do imperador brasileiro e que entre nós foi lançado com o título A marquesa de Santos. Tratase de uma das produções mais caras feitas até então na Argentina (NÚBILA, 1998, p. 338).

Em termos comerciais, destaca-se no período a implantação de uma representação da Distribuidora Panamericana no Brasil. Segundo o pesquisador Héctor R. Kohen, o produtor Miguel Machinandiarena, proprietário dos Estudios San Miguel e da Panamericana, veio ao Brasil em 1942 acompanhado por Augusto Alvarez e Eduardo Morera para instalarem um escritório da distribuidora argentina. No mesmo ano, Eduardo Morera entregou cópias de Melodías de América (Eduardo Morera, 1941) e En el viejo Buenos Aires (Antonio Momplet, 1942) para Alzira Vargas, a filha de Getúlio Vargas, e, em 1943, enviou um curtametragem para o próprio presidente da República. Tratava-se de uma evidente tentativa de aproximação com o governo brasileiro. Ainda em 1943, Miguel Machinandiarena veio ao Brasil e ofereceu um jantar na ABI (Associação Brasileira de Imprensa), no qual esteve presente Israel Souto - diretor da Divisão de Cinema e Teatro do DIP (Departamento de Imprensa e Propaganda) que, por sua vez, no ano seguinte, foi a Buenos Aires a convite dos Estudios San Miguel e da produtora Artistas Argentinos Asociados (KOHEN, 2000, p. 352-355). Para a imprensa argentina, Israel Souto declarou que a produção de cinema no Brasil tinha como óbice a existência de "poucos elementos artísticos", além de destacar positivamente a existência da exibição obrigatória de curtas-metragens nacionais (Declaraciones del dr. Israel Souto. Heraldo del Cinematografista, 26 abr. 1944, p. 58).

Conforme Michèle Lagny (1992, p. 101), as fronteiras nacionais não são impenetráveis e a "circulação dos filmes de um país para o outro acarreta todo um jogo de influências recíprocas". Outrossim, é necessário observar com essa historiadora que a produção industrial com base no capital privado tende a buscar o mercado 
exterior, da mesma forma que outros ramos industriais (1992, p. 100). A produção argentina almejou ocupar ao longo dos anos 1930 e 1940 parte do mercado da América Latina, além da alguns países europeus como a Espanha, o que incluiu a tentativa de ampliar o seu acesso ao mercado brasileiro.

\section{Adhemar Gonzaga visita Buenos Aires}

As visitas dos profissionais do meio cinematográfico de um país ao outro eram relativamente constantes no período 1930-1945. O ator Armando Louzada foi a Buenos Aires em 1940 e aproveitou para conhecer os estúdios locais (LOUZADA, 1940). E José A. Mentasti, um dos chefes da Argentina Sono Films, veio ao Rio de Janeiro nesse mesmo ano e deu longa entrevista para a imprensa local clamando por mais espaço nas salas de cinema para as produções da nação vizinha (MENTASTI, 1940) - essa declaração, aliás, reforça a asserção de Michèle Lagny apontada acima.

Mas, antes desses visitantes, quem esteve na Argentina, no ano de 1934, foi o principal produtor do cinema brasileiro, Adhemar Gonzaga, que em 1930 criara a Cinédia. Segundo suas próprias palavras ao jornal A Noite, em entrevista publicada em 1932, ele tinha os seguintes objetivos com a Cinédia:

Vamos produzir bons filmes, com a vantagem de terem espírito e o pensamento brasileiros. Não apenas para mostrar as belezas naturais aos estrangeiros, mas visando à educação de nosso povo. (apud GONZAGA, 1987, p. 11).

Esse trecho da entrevista deixa perceber claramente que as ideias do crítico de cinema Adhemar Gonzaga, expostas reiteradamente em Para todos - entre 1924 e 1926 - e em Cinearte - a partir de 1926 - , estavam sendo retomadas no contexto da agenda políticocultural do governo formado com a Revolução de 1930. Em artigo datado de 1926, Gonzaga já defendia o papel ideológico do cinema para a formação da nacionalidade brasileira: 
O Cinema se tornou um fator de peso no comércio internacional, só por seu intermédio é que se conseguirá fazer propaganda das coisas maravilhosas da nossa terra, e ainda com ele ensinaríamos aos brasileiros a serem brasileiros e não pernambucanos, baianos, paulistas etc. (GONZAGA, 1926).

No entanto, também havia diferenças cruciais nas posições de Gonzaga antes e depois de 1930. Nesse mesmo artigo de 1926, ele atacava o filme "natural" - ou seja, a não ficção - e defendia que o "posado" - a ficção - era "o único que nos [aos brasileiros] adianta”. Paulo Emílio Salles Gomes (1974, p. 308-309) observa que o "natural" garantia "a continuidade do cinema brasileiro", enquanto o "posado" colocava "em risco a própria estabilidade e a permanência da cinematografia nacional”; mas Adhemar Gonzaga não tinha consciência da estrutura econômica da produção brasileira nos anos 1920, e seus objetivos tinham por base "modelos longínquos que só tinham a ver conosco o fato de os consumirmos". Ou seja, ao mirar em Hollywood, Gonzaga não atentava que o filme "natural" permitia aos produtores continuar na atividade ao responder às demandas das elites econômicas e políticas de filmagens que registrassem o seu poder; já a ficção não encontrava lugar nas salas de cinema e, mesmo ao ser exibida, poucas vezes tinha público, o que levava à descapitalização dos produtores.

Conforme sabemos, outra será a postura de Adhemar Gonzaga na década seguinte, ainda mais diante da Lei 21.240, de 1932, que garantia a exibição compulsória do filme de curta-metragem de caráter educativo. A Cinédia já a partir de 1933 produziu curtas-metragens documentários como Ameba (Edgard RoquettePinto) e Como se faz um jornal moderno (Adhemar Gonzaga) (GONZAGA, 1987, p. 159).

Quando da viagem de Gonzaga à Argentina em 1934, além desses e de outros filmes curtos, a Cinédia já havia lançado comercialmente os seguintes longas-metragens: Lábios sem beijos (Humberto Mauro, 1930), Mulher (Octavio Gabus Mendes, 1931), Ganga bruta (Humberto Mauro, 1933) e A voz do Carnaval (Adhemar Gonzaga e Humberto Mauro, 1933). É de notar que 
as três primeiras produções obedeçam ao programa do crítico recém-convertido em produtor: trata-se de películas de ficção interpretadas pelo que se pretendia o star system da produtora e com forte destaque para os desencontros e encontros amorosos; outrossim, no caso do primeiro e do terceiro filmes, a ambientação dominante era a da alta sociedade. Já A voz do Carnaval foi uma produção caracterizada pelas filmagens bastante rápidas e que apresentava diversos números com músicas de sucesso, tais como Linda morena - de Lamartine Babo - e Fita amarela - de Noel Rosa -, além de "um entrecho cômico" com Palitos e Jararaca, entre outros artistas (GONZAGA, 1987, p. 42-43).

Afigura-se que Adhemar Gonzaga, diante do custo elevado dos três primeiros filmes, do investimento nos estúdios e da falta de recuperação financeira nas bilheterias, começava a agir menos como crítico e mais como produtor, daí a importância de A voz do Carnaval na filmografia da Cinédia.

E por que Gonzaga foi à Argentina? É sabido o seu interesse em acompanhar de perto o desenvolvimento da indústria cinematográfica em Hollywood, o que já havia motivado três viagens suas aos Estados Unidos, em 1927, 1929 e 1932 (GONZAGA; AQUINO, 1989, p. 150). No entanto, o cinema argentino, que logo apresentaria alto grau de desenvolvimento, ainda buscava se estruturar com a fundação de empresas como a Lumiton - criada em 1932 - e a Argentina Sono Films em 1933. No ano de 1933, foram produzidos apenas seis longasmetragens e no ano seguinte, sete, números que ainda não discrepavam do cinema brasileiro, cuja produção nesses mesmos anos foi, respectivamente, de dez e sete longas.

As motivações podem e devem ter sido diversas, mas o que possibilitou e/ou deu impulso fundamental para o jornalista e produtor Adhemar Gonzaga viajar à Argentina foi o cinema norteamericano. É de notar que Gonzaga continuava ligado à revista Cinearte, e esta, conforme é sabido, tinha na cobertura do cinema hollywoodiano o seu principal eixo.

Em 1934, o astro Ramón Novarro fez uma grande excursão pela América do Sul. Hoje pouco lembrado, esse ator de origem 
6. De origem chilena, Carlos

Borcosque, após viver em Hollywood, foi contratado pela Sono Films e se fixou na Argentina a partir de 1938 como diretor. Realizou, entre muitos outros filmes, obras importantes como Alas de mi patria

(1939), Y mañana serán hombres (1939) e El tambor de Tacuarí (1948)

(OLIVERI, 2011, p. 23-26). mexicana estrelou filmes da MGM de enorme sucesso de público, tais como O bem amado (Ben Hur, Fred Niblo, 1925), O pagão (The pagan, W. S. van Dyke, 1929), Mata Hari (George Fitzmaurice, 1931) - no qual contracenava com Greta Garbo - e Uma noite no Cairo (The barbarian, Sam Wood, 1933). Nessa excursão, que incluiu o Brasil, o Uruguai e a Argentina, Ramón Novarro apresentou-se em espetáculos ao vivo na companhia de sua irmã Carmen Samaniego, nos quais ele cantava e dançava. Saindo dos Estados Unidos em abril de 1934, no navio Northern Prince, ele foi acompanhado também por Carlos Borcosque ${ }^{6}$ - que fora seu assistente de direção na película La Sevillana (1931), versão em espanhol de Sevilha dos meus amores (Call of the flesh, Charles Brabin, 1930), ambas com Novarro no elenco. A chegada ao Rio de Janeiro e a saída de lá levaram grandes multidões ao porto. Em Montevidéu e em Buenos Aires, sua estadia também trouxe muita gente para as ruas a fim de vê-lo. O ator ainda retornou ao Rio de Janeiro, onde permaneceu vários dias (SOARES, 2010, p. 197-199). Nessa estada no Rio, Ramón Novarro apresentou-se no Palácio Teatro no final de junho; e, a seguir, foi a São Paulo, onde fez espetáculos no Cine Odeon a partir do início do mês seguinte (Folha da Manhã, 21 jun. 1934, p. 12). De Santos, o astro voltou para os Estados Unidos no dia 12 de julho (Folha da Manhã, 12 jul. 1934, p. 13). O programa da primeira apresentação de Ramón Novarro e sua irmã em São Paulo, ocorrido no Odeon a 3 de julho, foi divulgado pela imprensa:

$1^{\circ}$ - Ouverture pela grande orquestra de 25 professores sob a regência do maestro argentino Eduardo Armani; $2^{\circ}$ - RN numa canção do filme Uma noite no Cairo; $3^{\circ}$ - RN na canção "El Platero"; $4^{\circ}$ - Carmencita Samaniego no bailado "Alegrias", de Valverde; $5^{\circ}$ - RN em "Charming", do filme O Bem amado; $6^{\circ}$ - RN na "Serenata del Paltor", do filme O Bem amado; $7^{\circ}$ - Carmencita no bailado "La Farruca"; $8^{\circ}$ - RN em um número de surpresa; $9^{\circ}$ - Sinfonia pela orquestra; $10^{\circ}$ - RN e Carmencita em "Mírala bien". (Folha da Manhã, 4 jul. 1934, p. 16). 
A Folha da Manhã noticiou que os espetáculos em São Paulo tiveram ótimo público. Ramón Novarro chegou mesmo a interpretar a canção brasileira Se a lua contasse, que, ainda segundo o jornal, ele cantou "com muita graça e em muito bom português" (Folha da Manhã, 6 jul. 1934, p. 6).

Quando da primeira chegada de Ramón Novarro ao Rio de Janeiro, em abril de 1934, Cinearte destacou o fato e publicou duas páginas com fotos do ator, sendo uma cobrindo os passeios que ele fez pela cidade e outra da despedida no porto. Esta página apresenta uma imagem da multidão no cais diante do navio. A legenda da foto é a seguinte:

O "adios" [de Ramón Novarro] ao Rio, na memorável tarde de 20 de abril, vendo-se a bordo o diretor de "Cinearte", Adhemar Gonzaga, que partiu para Buenos Aires acompanhando o astro da M.G.M. (Cinearte, 1 maio 1934, p. 6) [grifou meu].

Ou seja, Gonzaga teve como uma das motivações da sua viagem a Buenos Aires a cobertura da turnê de Ramón Novarro na América do Sul. Uma vez na capital argentina, o jornalista e produtor brasileiro aproveitou para, além de fazer o trabalho jornalístico, também travar contatos com a cinematografia local. No Arquivo Cinédia, é possível encontrar fotos dele nos estúdios da Lumiton, o que demonstra cabalmente os contatos aos quais me referi. É importante observar que, em anotações apensas às fotos, Gonzaga identifica a presença de Carlos Alberto Pessano, chefe de redação da revista Cinegraf, a homóloga de Cinearte na Argentina - ou seja, ambas eram revistas ricamente ilustradas por fotos e voltadas para os fãs de cinema, com uma cobertura marcadamente direcionada para Hollywood. Uma das fotos apresenta ambos no set de filmagem da película Ayer y hoy (Enrique T. Susini, 1934), ao de lado de atores e técnicos. Aparentemente, foi Pessano quem ajudou a introduzir o produtor brasileiro no universo cinematográfico local. 
7. Carta de Carlos Alberto Pessano para Adhemar Gonzaga. [S.1.]: 1934. Arquivo Cinédia. Rio de Janeiro.

8. Carta de Carlos Alberto Pessano para Adhemar Gonzaga. [S.1.]: 14 jul. 1934. Arquivo Cinédia, Rio de Janeiro.
Carlos Alberto Pessano era um crítico de corte conservador e bastante respeitado na imprensa argentina. Apesar de Cinegraf ser dedicada, sobretudo, ao produto hollywoodiano, Pessano, por meio da coluna "Primer Plano", frequentemente se referia à produção nacional com posturas "tão exacerbadamente normativas quanto moralistas" (CAMPODÓNICO, 2005, p. 59) - o que não deixa de lembrar a perspectiva de Adhemar Gonzaga nos anos 1920. Pessano seria nomeado, em 1936, diretor técnico do então recém-criado Instituto Cinematográfico Argentino, voltado para a produção de documentários de cunho informativo e educativo. Esse era também o órgão responsável pelo veto à exportação de filmes argentinos que pudessem criar uma imagem negativa do país no exterior (MARANGHELLO, 2000, p. 32 e 45).

É de observar que a relação entre Gonzaga e Pessano estendeuse para além da viagem, pois o brasileiro indicou Gilberto Souto, o correspondente de Cinearte em Hollywood, para também ser correspondente de Cinegraf 7 , o que de fato ocorreu por algum tempo. Pessano, na sua correspondência a Gonzaga, pede que este envie informações sobre o cinema brasileiro, a fim de "publicizar" nossa produção na Argentina por meio de Cinegraf. Ao mesmo tempo, prontifica-se a enviar fotos e notícias; ademais, ele fez comentários entusiasmados em torno de Riachuelo, película que, apesar de baseada em um "sainete vulgar", estaria sendo "realizada com um critério verdadeiramente cinematográfico" e seria "uma

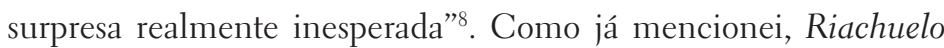
foi estrelada pelo célebre cômico Luis Sandrini, e seu público foi grande, fazendo sucesso não apenas em Buenos Aires mas também no interior do país e na América Latina, a qual "sonhou com a noite de Buenos Aires e imitou a fala entrecortada de Luis Sandrini” (ESPAÑA, 1984, p. 59).

Cumpre ainda anotar que no Arquivo Cinédia há bastante material sobre a Argentina no que tange às informações sobre o mercado local e a respeito das diversas propostas de legislação nos anos 1930 e 1940. 


\section{Considerações finais}

Essa passagem de Adhemar Gonzaga por Buenos Aires e a documentação que integra o Arquivo Cinédia, por si sós, indicam a existência de relações entre as cinematografias brasileira e argentina nos anos 1930 e 1940, e não de dois entes estanques, sem quaisquer contatos. Afigura-se importante assinalar isso, pois a historiografia do cinema, com os seus recortes fortemente vinculados às fronteiras de cada nação e eivada por uma perspectiva evolucionista, construiu uma imagem segundo a qual o contato entre as cinematografias do subcontinente latino-americano teria florescido apenas nos anos 1960, sob a égide dos Cinemas Novos.

Outrossim, o fato de a visita de um astro do cinema norteamericano à América do Sul ter sido o motor da viagem do principal produtor brasileiro ao país vizinho demonstra o papel importante que Hollywood jogou, ainda que involuntariamente, para o avanço dos contatos cinematográficos na América Latina. O internacionalismo da dominação do cinema norteamericano possibilitou, sem que isso fizesse parte do programa de Hollywood, uma maior aproximação entre as cinematografias da Argentina e do Brasil.

Finalmente, parece muito provável a hipótese de que a estratégia de Adhemar Gonzaga passava nesse momento pela composição com o cinema dominante, e não pela oposição a ele, isso até pelo fato de que o produtor continuava ligado à Cinearte e, inclusive, nesse momento, ocupava a direção da revista. Além de querer emular a forma e o modo de produção do filme hollywoodiano, Gonzaga não parecia disposto a confrontar as majors, mas sim a compor com elas; daí, talvez, a falta de reivindicação de uma política protecionista por parte do Estado que impedisse a importação do produto estrangeiro, contentando-se com a exibição obrigatória do curta-metragem tal como previsto na Lei 21.240 - o que implicava confronto com os exibidores, e não com as distribuidoras de filmes estrangeiros. A “ambigüidade", a qual se refere Paulo Emílio Salles Gomes (1974, p. 321), que "habitava o íntimo de Adhemar Gonzaga", lastreada no fato de que ele, como todos os fãs da sua época, aprendera a amar o cinema com base no filme norte-americano e admirava Hollywood incondicionalmente, mesmo buscando com todas as suas forças desenvolver uma indústria cinematográfica nacional, continuava a assombrar o jornalista e agora principal produtor brasileiro. 


\section{Referências}

CAMPODÓNICO, R. H. Trincheras de celuloide: bases para una historia político-económica del cine argentino. Madrid; Havana: Fundación Autor; Universidad de Alcalá; FINCL, 2005.

ESPAÑA, C. Medio siglo de cine. Buenos Aires: Abril, 1984.

FREIRE, R. de L. Carnaval, mistério e gangsters: o filme policial no Brasil (1915-1951). Tese (doutorado) - Universidade Federal Fluminense, Niterói, 2011.

GETINO, O. Cine argentino: entre lo posible y lo deseable. Buenos Aires: Ciccus, 1998.

GOMES, P. E. S. Humberto Mauro, Cataguases, Cinearte. São Paulo: Perspectiva; São Paulo: ed. da Universidade de São Paulo, 1974.

Pequeno cinema antigo. In: Cinema: trajetória no subdesenvolvimento. Rio de Janeiro: Paz e Terra; Rio de Janeiro: Embrafilme, 1980.

GONZAGA, A. 50 Anos de Cinédia. Rio de Janeiro: Record, 1987. "Filmagem brasileira". Para Todos, Rio de Janeiro, v. 8, n. 370, 16 jan. 1926.

GONZAGA, A.; AQUINO, C. Gonzaga por ele mesmo: memórias e escritos de um pioneiro do cinema brasileiro. Rio de Janeiro: Record, 1989.

KOHEN, H. R. "Estudios San Miguel: ruleta, películas y política”. In: ESPAÑA, C. (Org.). Cine argentino: industria y clasicismo 1933/1956. V. 1. Buenos Aires: Fondo Nacional de las Artes, 2000.

LAGNY, M. De l'histoire du cinéma: méthode historique et histoire du cinéma. Paris: Armand Colin, 1992.

LOUZADA, A. "Em visita a Buenos Aires". Cine-Rádio Jornal, Rio de Janeiro, v. 3, n. 95, 9 maio 1940.

LUSNICH, A. L. El drama social-folclórico: el universo rural en el cine argentino. Buenos Aires: Biblos, 2007. 
MARANGHELLO, C. Breve historia del cine argentino. Barcelona: Laertes, 2005.

"Cine y Estado: del proyecto conservador a la difusión peronista”. In: ESPAÑA, C. (Org.). Cine argentino: industria y clasicismo - 1933/1956. V. 2. Buenos Aires: Fondo Nacional de las Artes, 2000

MENTASTI, J. A. "O cinema argentino precisa de uma oportunidade no Brasil!". Cine-Rádio Jornal, Rio de Janeiro, v. 3, n. 108,1 ago. 1940.

NÚBILA, D. di. Historia del cine argentino: la época de oro. Buenos Aires: Ediciones del Jilguero, 1998.

OLIVERI, R. G. "Carlos Borcosque”. In: RODICIO, E. C. (Org.). Diccionario del cine iberoamericano: España, Portugal y América. V. 2. Madrid: Sociedad General de Autores y Editores; Madrid: Fundación Autor, 2011.

PARANAGUÁ, P. A. Le cinéma em Amérique Latine: le miroir éclaté. Paris: L'Harmattan, 2000.

SOARES, A. Beyond paradise: the life of Ramón Novarro. Jackson: University Press of Mississipi, 2010.

VIANY, A. Introdução ao cinema brasileiro. Rio de Janeiro: Instituto Nacional do Livro, 1959. 